7 Guangdong, China

* Zeng Rong

\title{
A novel amidase signature family amidase from the marine actinomycete Salinispora arenicola CNS-205
}

\author{
Ma Yanling ${ }^{1}$ Zhang Xinfeng ${ }^{2}$ Zeng Rong*
}

${ }^{1}$ College of food science and engineering, Foshan University, Foshan,

${ }^{2}$ Department of technical research and development, Foshan Haitian (Gaoming) Flavouring \& Food Co., LTD., Foshan, Guangdong, China

E-mail: zengrong@163.com 


\section{Abstract}

We cloned a new gene from the amidase signature (AS) family, designated am, from the marine actinomycete Salinispora arenicola CNS-205. As indicated by bioinformatics analysis and site-directed mutagenesis, the AM protein belonged to the AS family. AM was expressed, purified, and characterised in Escherichia coli BL21 (DE3), and the AM molecular mass was determined to be $51 \mathrm{kDa}$. The optimal temperature and $\mathrm{pH}$ were $40{ }^{\circ} \mathrm{C}$ and $\mathrm{pH} 8.0$, respectively. AM exhibited a wide substrate spectrum and showed amidase, aryl acylamidase, and acyl transferase activities. AM had high activity towards aromatic and aliphatic amides. The AM substrate specificity for anilides was very narrow; only propanil could be used as an effective substrate. The extensive substrate range of AM indicates it may have broad potential applications in biosynthetic processes and biodegradation.

Keywords AM-amidase signature (AS) family·Aryl acylamidase·Acyl transferase activity·Propanil

\section{Introduction}

Carboxylic acid amides can be hydrolysed by amidases (EC 3.5.1.4), forming carboxylic acids and ammonia. Most amidases also produce hydroxamic acids through their acyltransferase activity (Asano et al. 1982; Fournand et al. 1998). Amidases are very important for chemical industrial synthesis and for control of environmental pollution. 
Amidases can be divided into two categories (Chebrou et al. 1996; Fournand and Arnaud 2001). The first category is the nitrilase superfamily, which is characterised by a cysteine residue and includes aliphatic amidases. The second category is the amidase signature (AS) family, which has a conserved GGSS signature in the amino acid sequence (Mayaux et al. 1990; Chebrou et al. 1996). Amidases are extensively present in bacteria, archaea and eukaryotes (d'Abusco et al. 2001; Galadari et al. 2006; Neu et al. 2007; Ohtaki et al. 2010; Politi et al. 2009).

The marine actinomycete Salinispora arenicola CNS-205 produces many bioactive natural products, including saliniketals $\mathrm{A}$ and $\mathrm{B}$, which were originally isolated by Fenical and co-workers in 2006 (Fenical et al. 2006). Genome sequencing of the strain S. arenicola CNS-205 identified a gene encoding a putative amidase, named AM, which belongs to the AS family. The amidase activity of AM was confirmed, and its catalytic parameters and optimal conditions were determined. This enzyme was shown to have an abnormally wide substrate spectrum and activities.

\section{Materials and methods}

\section{Chemicals}

The chemicals used in this paper were graded as analytical reagents and purchased from J\&K Scientific Company (Beijing, China).

\section{Bacterial strains and culture conditions}


S. arenicola CNS-205 was cultured in liquid ISP2S (0.4\% yeast extract, $1 \%$ malt extract, $0.4 \%$ glucose, and $7 \%$ sea salt; $\mathrm{pH} 7.3$ ) in an incubator with rotation at $28{ }^{\circ} \mathrm{C}$ and $220 \mathrm{rpm}$ and harvested after $2-3$ days to obtain the genomic DNA.

\section{Cloning of the am gene}

The genomic DNA of $S$. arenicola CNS-205 was extracted. Genes encoding potential AS family amidases were identified through BLASTP analysis (http://www.ncbi.nlm.nih.gov/blast). The primers used for the polymerase chain reaction of the am ORF were am-F (5'GGGCATATGGCGGTGCAGGACATCA-3') and am-R (5'CAGGAATTCCAGTTTCGTCATGCCC-3'). The NdeI and EcoRI sites (underlined) were used to clone am into the protein expression vector pET-28a $(+)$ (Novagen).

\section{AM expression and purification}

Escherichia coli BL21 (DE3) carrying pET28a(+)-am was grown in Luria-Bertani medium with $100 \mu \mathrm{g} \mathrm{ml} \mathrm{l}^{-1}$ ampicillin at $37{ }^{\circ} \mathrm{C}(11$ medium was inoculated with $1 \%$ inoculum from a $20 \mathrm{ml}$ overnight culture). The cultures were induced with $0.1 \mathrm{mM}$ isopropyl- $\beta$-D-thiogalactopyranoside at $\mathrm{OD}_{600}=0.6$ and incubated for $20 \mathrm{~h}$ at $16{ }^{\circ} \mathrm{C}$. Then, the cultures were centrifuged at $5,000 \mathrm{rpm}$ for $10 \mathrm{~min}$ at $4{ }^{\circ} \mathrm{C}$. The cell pellet was resuspended in prechilled binding buffer $(20 \mathrm{mM}$ Tris- $\mathrm{HCl}, \mathrm{pH} 8.0,0.5$ $\mathrm{mM} \mathrm{NaCl}$, and $5 \mathrm{mM}$ imidazole) and lysed by sonication on ice $(60 \%$ 
amplitude, $4 \mathrm{~s}$ on and $10 \mathrm{~s}$ off). The supernatant was harvested after centrifugation at $15,000 \mathrm{rpm}$ for $30 \mathrm{~min}$ at $4{ }^{\circ} \mathrm{C}$. Then, the supernatant was loaded onto a His-Bind $\mathrm{Ni}$ resin column pre-equilibrated with binding buffer (GE Healthcare). An imidazole step gradient was used, and the $\mathrm{His}_{6}$-AM protein $(50,100,200,400$, and $800 \mathrm{mM})$ was recovered in elution buffer $(20 \mathrm{mM}$ Tris- $\mathrm{HCl}, \mathrm{pH} 8.0$, and $0.5 \mathrm{mM} \mathrm{NaCl})$. Then, SDS-PAGE and HPLC-MS (Thermo) were used to analyse the fractions with $\mathrm{His}_{6}$-AM. The supernatant containing $\mathrm{His}_{6}-\mathrm{AM}$ was further purified with PD-10 desalting columns (GE Healthcare) after it was concentrated through a VIVASPIN concentrator. The protein concentration was quantified with a NANODROP 2000c (Thermo), and a Thermo Hypersil GOLD C4 column $(1.9 \mu, 100 \times 2.1 \mathrm{~mm})$ was used. The recombinant proteins were assessed with HPLC-ESI-HRMS and eluted with a gradient of $0.1 \%$ formic acid (A) and $\mathrm{CH}_{3} \mathrm{CN}$-containing $0.1 \%$ formic acid (B). The elution program was $2 \% \mathrm{~B}$ for $3 \mathrm{~min}, 2$ to $20 \% \mathrm{~B}$ for $1 \mathrm{~min}, 20$ to $70 \%$ B for $16 \min , 70$ to $90 \%$ B for $1 \mathrm{~min}, 90 \%$ B for $4 \min , 90$ to $2 \%$ B for $1 \mathrm{~min}$, and $2 \% \mathrm{~B}$ for $4 \mathrm{~min}$ at a flow rate of $0.2 \mathrm{ml} \mathrm{min}^{-1}$. A Orbitrap mass spectrometer (Thermo) was used in positive ion mode, with scanning from $\mathrm{m} / \mathrm{z} 300$ to 2,000. Xcalibur software (v.1.1; Thermo Finnigan) was used for analysis, and the data were processed and deconvoluted.

\section{Amidase assays}


The purified AM was resuspended in buffer $(\mathrm{pH} 8.0,20 \mathrm{mM}$ Tris- $\mathrm{HCl}$, $10 \%$ glycerol and $100 \mathrm{mM} \mathrm{NaCl})$. The assays were performed with $1 \mu \mathrm{g}$ purified $\mathrm{AM}$ in $20 \mathrm{mM}$ Tris- $\mathrm{HCl}, \mathrm{pH} 8.0,100 \mathrm{mM} \mathrm{NaCl}$ at $35^{\circ} \mathrm{C}$. The phenol-hypochlorite ammonia method (Weatherburn 1967) was used to assess the amidase activity, which yielded ammonia. The amount of enzyme catalysing the release of $1 \mu \mathrm{mol} \mathrm{NH}_{3} /$ min was defined as one unit of enzyme activity. The Hanes-Woolf method was used to estimate the $K_{\mathrm{m}}$ and $\mathrm{V}_{\mathrm{max}}$, and the $k_{\text {cat }}$ and $k_{\mathrm{cat}} / K_{\mathrm{m}}$ values were determined, indicating a molecular mass of $51 \mathrm{kDa}$. Control reactions were performed without AM.

\section{Aryl acylamidase activity assay}

The aryl anilide pesticides propanil, butachlor and acetochlor were assessed as substrates to determine the aryl acylamidase activity of AM. The aryl acylamidase activity was verified following the method of Shen et al. (2012) as follows: $1 \mu \mathrm{g}$ of $\mathrm{His}_{6}$-AM was added to $0.2 \mathrm{mM}$ anilide in $1 \mathrm{ml}$ of $20 \mathrm{mM}$ Tris- $\mathrm{HCl}, \mathrm{pH} 8.0,100 \mathrm{mM} \mathrm{NaCl}$ and incubated at $35^{\circ} \mathrm{C}$. Addition of $\mathrm{HCl}$ changed the $\mathrm{pH}$ to 3 , and the sample was extracted with ethyl acetate, terminating the reaction. This organic layer was dried and re-dissolved in methanol. Reverse-phase HPLC (Shimadzu LC-20 AD, Waters 2998 photodiode array detector) with a Thermo C18 cartridge (particle size $3 \mu ; 2.1 \times 150 \mathrm{~mm}$ ) and $250 \mathrm{~nm}$ detection wavelength was used to recognise the reaction products, with $2: 3 \quad 0.1 \%$ formic 
acid/methanol (isocratic elution mode) for $20 \mathrm{~min}$ at a flow rate of $0.2 \mathrm{ml}$ $\min ^{-1}$.

\section{Hydroxylamine-acyl transferase activity assay}

The acyl transfer activity was detected as described by Fournand et al. (1998). All experiments were performed at $35{ }^{\circ} \mathrm{C}$ for $10 \mathrm{~min}$, and the reaction system was as follows: $1 \mu \mathrm{g}$ of $\mathrm{AM}$, hydroxylamine hydrochloride (100 mM, pH 7.0), and amide or anilide $(1 \sim 25 \mathrm{mM})$ in buffer (20 mM Tris-HCl, pH 8.0, $100 \mathrm{mM} \mathrm{NaCl})$. An acidic solution of $\mathrm{FeCl}_{3}(0.133 \mathrm{M}$ in $0.68 \mathrm{M} \mathrm{HCl})$ was adopted to terminate the reactions. The supernatant was initially centrifuged at $12,000 \mathrm{rpm}$ for $10 \mathrm{~min}$ and subsequently collected, and the hydroxamate concentration was measured at $\lambda=500 \mathrm{~nm}$. The blank control experiments were performed without AM. The optical density of the experimental groups (marked A1) was determined. Additionally, the control group (marked A2) was assessed to determine the concentration $(\mathrm{C})$ of hydroxamate $\mathrm{C}=(\mathrm{A} 1-\mathrm{A} 2) / \varepsilon \mathrm{L}$ (A refers to the optical density, $\varepsilon$ denotes the coefficient of molar extinction, and $\mathrm{L}$ indicates the layer thickness). Different substrates have different $\varepsilon$ values: propionamide, $1,029 \mathrm{M}^{-1} \mathrm{~cm}^{-1}$; hydroxamate derivative of acetamide, 996 $\mathrm{M}^{-1} \mathrm{~cm}^{-1}$; propanil, 1,029 $\mathrm{M}^{-1} \mathrm{~cm}^{-1}$; isobutyramide, $1,016 \mathrm{M}^{-1} \mathrm{~cm}^{-1}$. The control groups did not have AM. One unit of enzyme activity was defined as the amount of enzyme required to catalyse the formation or hydrolysis of $1 \mu \mathrm{mol}$ of substrate or product every minute. 


\section{Effects of temperature and $\mathrm{pH}$ on enzyme activity}

For determination of the optimal temperature, the experiments were performed in buffer (20 mM Tris-HCl, $\mathrm{pH} 8.0,100 \mathrm{mM} \mathrm{NaCl})$ with 20 $\mathrm{mM}$ of the substrate benzamide. Thermo stability was detected by preincubation of the protein for $1 \mathrm{~h}$ at different temperatures. Then, the residual activity was tested at $35^{\circ} \mathrm{C}$. For determination of the optimal $\mathrm{pH}$, the experiments were performed in various buffers as follows: $0.1 \mathrm{M}$ sodium acetate buffer $(\mathrm{pH} 4.0,4.5,5.0,5.5$, and 6.0), $0.1 \mathrm{M}$ potassiumphosphate buffer ( $\mathrm{pH} 6.0,6.5,7.0,7.5,7.8$, and 8.5), and $0.1 \mathrm{M}$ Tris-HCl buffer ( $\mathrm{pH} 7.5,8.0,8.5,9.0,9.5$, and 10.0). For the $\mathrm{pH}$ stability detection, the experiments were performed in buffers with $\mathrm{pH}$ values that ranged from 4.0 to 10.0 with incubation at $25{ }^{\circ} \mathrm{C}$ for $1 \mathrm{~h}$; then, the residual protein activity was tested at $35^{\circ} \mathrm{C}$.

\section{Impact of metal ions and other reagents}

The impact of metal ions $\left(\mathrm{Ni}^{2+}, \mathrm{Ba}^{2+}, \mathrm{Zn}^{2+}\right.$ and $\left.\mathrm{Ca}^{2+}\right)$ and chemical agents (1,10-phenanthroline, EDTA, SDS and PMSF) on the amidase activity was detected. The samples were preincubated for 10 min at $35^{\circ} \mathrm{C}$ with benzamide as a substrate, and then, the amidase activity was determined as described previously.

\section{Site-directed mutagenesis of am}

Site-directed mutagenesis primer pairs (Table 1) were designed to produce mutated am with a QuikChange site-directed mutagenesis kit 
176 (Stratagene). The recombinant plasmid pET-28a(+)-am served as a

template in the mutagenesis reactions. The PCR products were purified by agarose gel electrophoresis, and the DNA bands with the appropriate sizes were eluted from the gel pieces. Then, the plasmid DNA was digested with DpnI and transformed into competent E. coli BL21 (DE3) cells. Three mutant (K84A, S158A, and S182A) plasmids were constructed with this technique and were verified through DNA sequencing. The mutant proteins were expressed, purified, and analysed as described above.

\section{Nucleotide sequence accession number}

The nucleotide sequence of am was stored in GenBank with a sequence ID of CP000850.1.

\section{Results}

\section{Sequence analysis of the am gene}

The amino acid sequence of AM was compared to sequences of known amidases accessible in the GenBank database. The comparisons showed that AM shared $29-45 \%$ identity with several enzymes, including an amidase from Rhodococcus sp. N771 (45\% identity), an amidase from Thermus thermophilus HB8 (31\% identity), the aspartyl/glutamyl-tRNA amidotransferase subunit A from T. thermophilus HB8 (33\% identity), and the aspartyl/glutamyl-tRNA amidotransferase subunit A from Thermotoga maritima MSB8 (28\% identity). Additionally, we confirmed 
the presence of Ser-Ser-Lys, the highly conserved catalytic triad of the AS family, in the enzyme amino acid sequence (Fig 1).

\section{Fig 1. Comparison of the amino acid sequences of the AM and homologous}

proteins. Sequence alignment of the amino acid sequence of AM showing the high homology with the AS amidase (3A1K_A) from Rhodococcus Sp. N771, the Thermus thermophilus HB8 amidase (YP_145063.1), the T. thermophilus HB8 aspartyl/glutamyl-tRNA amidotransferase subunit A (YP_143839.1), and the Thermotoga maritima MSB8 aspartyl/glutamyl-tRNA amidotransferase subunit A (NP_229077.1). The alignment was produced by ClustalW. Multiple alignments were generated with BioEdit. The dark grey under the sequence indicates the residues of the Ser-Ser-Lys catalytic triad.

We demonstrated that this motif was the catalytic site through sitedirected mutagenesis (Table 1). Thus, we showed that AM of S. arenicola CNS-205 contains the highly conserved catalytic triad Ser-Ser-Lys and is a member of the AS family.

Table 1. Oligonucleotides used for site-directed mutagenesis

\begin{tabular}{cl}
$\begin{array}{c}\text { AM gene } \\
\text { allele }\end{array}$ & \multicolumn{1}{c}{ Mutagenic primer sets } \\
& GTG CCG GTG GCG GTC GCG GAG AAC ACC GCT GTG \\
K84A & G \\
& C CAC AGC GGT GTT CTC CGC GAC CGC CAC CGG CAC \\
& CGT ACC CCC GGT GGC $\frac{\text { GCG TCC GGT GGA TCG GCC G }}{(\mathrm{S})}$
\end{tabular}


S182A

C GGC CGA TCC ACC GGA CGC GCC ACC GGG GGT ACG

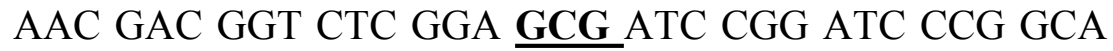
G

C TGC CGG GAT CCG GAT CGC TCC GAG ACC GTC GTT

The boldface type indicates the mutated amino acids.

\section{Expression and purification of AM}

The fusion protein $\mathrm{His}_{6}$-AM was overexpressed in E. coli BL21 (DE3). The purity of the purified fusion protein was greater than $90 \%$. The SDSPAGE results indicated that the molecular mass of the major band was $51.2 \mathrm{kDa}$ (Fig 2), which conformed to mass of the deduced protein sequence.

Fig 2. SDS-PAGE of AM-1 and its mutants. Lanes 1, protein molecular weight marker; 2, wild-type AM-1; 3, K84A; 4, S158A; and 5, S182A

To obtain the molecular mass of the proteins, we analysed the $\mathrm{His}_{6}$-AM fusion protein and three mutants (K84A, S158A, and S182A) by HPLCESI-HRMS. The molecular weights of the AM wild-type, K84A, S158A, and S182A were 51.037, 50.980, 51.021, and $51.021 \mathrm{kDa}$, which were consistent with the predicted values (Fig 3). 
Fig 3. HPLC-ESI-HRMS analysis of AM. WT (a), K84A (b), S158A (c) and S182A

(d). Extra minor peaks marked by asterisks denote glycosylation (+178 Da) of the Nterminal $\mathrm{His}_{6}$-tag added during the expression of the recombinant protein in E. coli (Geoghegan et al.1999)

\section{Effects of temperature and $\mathrm{pH}$ on $\mathrm{AM}$ activity and stability}

To determine the optimal temperature, we assessed the amidase activity at

a temperature range from 15 to $65{ }^{\circ} \mathrm{C}$ with benzamide as the substrate.

The AM activity peaked at $40{ }^{\circ} \mathrm{C}$, and it showed an excessively wide peak (Fig 4a). More than $50 \%$ of the residual activity was observed at temperatures from 30 to $50^{\circ} \mathrm{C}$. Thermo stability tests indicated moderate loss of amidase activity within $1 \mathrm{~h}$ up to approximately $45^{\circ} \mathrm{C}$ (Fig 4b). Only $9 \%$ of the activity was observed at $55^{\circ} \mathrm{C}$ after $1 \mathrm{~h}$, and the amidase activity was lost completely after $1 \mathrm{~h}$ at $60^{\circ} \mathrm{C}$.

247 The optimal $\mathrm{pH}$ for $\mathrm{AM}$ was determined in the buffers described in the

248 Materials and methods. Figure 4c indicates that AM was highly active different $\mathrm{pH}$ values, and the results indicated that more than $60 \%$ residual activity was observed between pH 4.5 and 10.0 (Fig 4d). 
Fig 4. Effects of $\mathrm{pH}$ and temperature on AM activity and stability. a min in buffers with varying $\mathrm{pH}$ values. b $\mathrm{pH}$ stability. The assays were performed in of the optimal temperature. The activity was measured in $20 \mathrm{mM}$ Tris- $\mathrm{HCl}, 100 \mathrm{mM}$ $\mathrm{NaCl}, \mathrm{pH} 8.0$, at $15-65{ }^{\circ} \mathrm{C}$ for $10 \mathrm{~min}$. d Thermal stability. The reactions were performed under optimal conditions after incubation of $\mathrm{AM}$ at the indicated temperature for $1 \mathrm{~h}$.

\section{Impact of metal ions and other reagents}

The majority of the metal ions, including $\mathrm{Ba}^{2+}, \mathrm{Ca}^{2+}, \mathrm{Zn}^{2+}$, and $\mathrm{Ni}^{2+}$, in the assays exerted no noticeable effect on the amidase activity of AM (Table

Table 2. Effects of metal ions and inhibitors on the amidase activity of AM

\begin{tabular}{|c|c|c|c|}
\hline $\begin{array}{l}\text { Reagent } \\
(1 \mathrm{mM})\end{array}$ & $\begin{array}{c}\text { Relative activity } \\
(\%)\end{array}$ & $\begin{array}{l}\text { Reagent } \\
(1 \mathrm{mM})\end{array}$ & $\begin{array}{c}\text { Relative activity } \\
(\%)\end{array}$ \\
\hline No addition & 100 & PMSF & $10.13 \pm 0.60$ \\
\hline $\mathbf{B a}^{2+}$ & $94.30 \pm 2.59$ & 1,10-Phenanthroline & $82.46 \pm 0.73$ \\
\hline $\mathrm{Ca}^{2+}$ & $88.60 \pm 2.13$ & EDTA & $77.64 \pm 0.92$ \\
\hline $\mathbf{Z n}^{2+}$ & $85.09 \pm 3.87$ & SDS & $51.78 \pm 0.27$ \\
\hline $\mathbf{N i}^{2+}$ & $96.93 \pm 1.90$ & & \\
\hline
\end{tabular}


serine hydrolases. However, the chelating agents EDTA and 1,10phenanthroline $(10 \mathrm{mM})$ resulted in only a $20-30 \%$ inhibition of AM hydrolysis, demonstrating that these chemicals did not chelate a possible divalent cation(s) required for the activity of the enzyme. The surfactant SDS showed a $48.22 \%$ inhibition of AM activity.

\section{Substrate spectrum}

To determine the substrate specificity of AM, we assessed whether the purified AM could hydrolyse different aromatic and aliphatic amides. The results showed that AM had high activity towards the aromatic and aliphatic amides, including acetamide, propionamide, propanil, benzeneacetamide and benzamide (Table 3 ).

Table 3. Substrate spectrum of AM

\begin{tabular}{llll}
\hline Substrate & \multicolumn{1}{c}{$\begin{array}{c}\text { Relative activity } \\
\mathbf{( \% )}\end{array}$} & $\begin{array}{l}\text { Substrate } \\
\text { Relative activity }\end{array}$ \\
\hline Acetamide & $103.79 \pm 0.46$ & Propanil & \multicolumn{1}{c}{$(\mathbf{\%})$} \\
Benzamide & 100 & Propanamide & $106.36 \pm 0.42$ \\
Benzeneacetami & & Isobutyrami & $18.02 \pm 0.72$ \\
d & $107.75 \pm 0.48$ & de & \\
Nicotinamide & $56.42 \pm 1.29$ & Acetochlor & 0 \\
Pyrazinamide & $43.01 \pm 2.76$ & Butachlor & 0 \\
\hline
\end{tabular}

a The activity with benzamide was defined as $100 \%$. All measurements were performed in triplicate

283 The aromatic amides, including nicotinamide and pyrazinamide, with 284 substitutions of one or two carbons in the ring by a nitrogen, had a 
very narrow, and the protein could not hydrolyse butachlor and acetochlor. Only propanil was a good substrate for AM.

Kinetic parameters for AM were estimated by the Hanes-Woolf method.

The $K_{\mathrm{m}}$ values for acetamide and propionamide were $3.36 \pm 0.17 \mathrm{mM}$ and

$3.33 \pm 0.08 \mathrm{mM}$ (Table 4).

Table 4. Kinetic parameters for $\mathrm{AM}$ amidase reaction

\begin{tabular}{|c|c|c|c|c|}
\hline Substrate & $K_{\mathrm{m}}(\mathrm{mM})$ & $\begin{array}{c}V_{\max } \\
\left(\mathrm{mM} \min ^{-1}\right)\end{array}$ & $k_{\text {cat }}\left(\mathrm{s}^{-1}\right)$ & $\begin{array}{c}k_{\text {cat }} / K_{\mathrm{m}} \\
\left(\mathrm{mM}^{-1} \mathrm{~s}^{-1}\right)\end{array}$ \\
\hline Acetamide & $3.36 \pm 0.17$ & $0.491 \pm 0.001$ & $63.89 \pm 0.20$ & $19.06 \pm 0.94$ \\
\hline Nicotinamide & $6.20 \pm 0.04$ & $0.293 \pm 0.006$ & $38.19 \pm 0.75$ & $6.16 \pm 0.12$ \\
\hline Propionamide & $3.33 \pm 0.08$ & $0.503 \pm 0.001$ & $65.54 \pm 0.08$ & $19.69 \pm 0.43$ \\
\hline Benzamide & $3.49 \pm 0.12$ & $0.508 \pm 0.005$ & $66.15 \pm 0.66$ & $18.95 \pm 0.72$ \\
\hline
\end{tabular}

${ }^{a}$ All substrates were tested at 25-200 mM, except for benzamide, which was insoluble above $50 \mathrm{mM}$

The anilide substrate range of AM was very narrow, and the protein could not hydrolyse acetochlor and butachlor. Only propanil was a good substrate for AM, but the $K_{\mathrm{m}}$ value could not be determined due to the low solubility of the compound.

\section{Site-directed mutagenesis}

The potential catalytic active site residues of AM were replaced by the

299 QuikChange site-directed mutagenesis kit. The mutants were overexpressed in E. coli BL21 (DE3) cells and further purified as 
conserved catalytic triad Ser-Ser-Lys.

\section{Discussion}

An isolate of $S$. arenicola CNS-205 identified by Fenical (Fenical et al. 2006) and co-workers in 2006 encodes a putative amidase. Sequence alignments of the primary AM sequence indicated that AM had a high similarity with the AS family and showed that AM contains the central GGSS signature, which is a typical characteristic of the AS family. The point mutation results also indicated that no hydrolytic activity could be detected in the K84A, S158A, and S182A mutants. These findings indicated that AM belongs to the AS family.

The effects of different metal ions and chemical reagents on AM activity were different. AM activity was affected by reducing agents, such as PMSF, and the results revealed that serine was the active site of the amidase. This result was consistent with the crucial role of $\mathrm{Ser}^{183}$, as revealed by site-directed mutagenesis experiments. A metal chelating agent (EDTA) did not impact the activity, indicating that a possible divalent cation(s) required for enzyme activity was not chelated by these chemicals.

Analysis of the substrate specificity of AM showed that the enzyme had high activity against short-chain aliphatic amide substrates (acetamide, isobutyramide and propanamide), which are typical substrates of the AS family. Interestingly, AM also hydrolyses ring amide substrates, such as 
aromatic and heterocyclic amides. The hydrolytic product of nicotinamide is nicotinic acid, a water-soluble B-complex vitamin, which has been extensively applied in treatment of schizophrenia, autoimmune diseases, hypercholesterolemia, diabetes and osteoarthritis. Benzoic acid, the hydrolytic product of benzamide, has antifungal activity and is extensively used as a preservative in production of processed and convenience foods.

AM also had aryl acylamidase activity against aniline substrates, including propanil (a commercial amide-containing pesticide), which was hydrolysed to produce 3,4-dichloroaniline. However, acetochlor and butachlor, which are structurally analogous to propanil, were not substrates for AM, indicating the anilide substrate range of AM was very narrow. Propanil, an acyl anilide herbicide, can contaminate the soil environment, and AM, by attacking the amide bonds in propanil, can

340 reduce its concentrations in soil. Thus, AM may have potential applications in bioremediation.

In addition to the amidase and aryl acylamidase activities, acyl transferase activity is an important characteristic as it produces 344 hydroxamic acids (Fournand et al. 1998). In this study, AM from $S$. arenicola CNS-205 had acyl transferase activity on anilide substrates, including propanil. The extensive substrate specificity range and acyl 
transferase activity indicate that AM has broad potential applications in biosynthesis processes and biodegradation.

Overall, a new amidase gene, AM, was cloned from S. arenicola CNS-205, and the amidase, aryl acylamidase, and acyl transferase activities of the enzyme were verified. These activities indicate that AM has a broad substrate spectrum. AM may be a potential agent for environmental remediation and for the biosynthesis of novel amides by virtue of these characteristics, as well as the broad $\mathrm{pH}$ tolerance of the enzyme.

\section{References}

Asano Y, Tachibana M, Tani Y, Yamada H, Purification and characterization of amidase which participates in nitrile degradation. Agric Biol Chem. 1982; 46:1175-1181.

Chebrou H, Bigey F, Arnaud A, Galzy P, Study of the amidase signature group. Biochim Biophys Acta. 1996; 1298:285-293.

Fournand D, Arnaud A, Aliphatic and enantioselective amidases: from hydrolysis to acyl transfer activity. J Appl Microbiol. 2001; 91:381-393.

Fournand D, Bigey F, Arnaud A, Acyl transfer activity of an amidase from Rhodococcus sp. strain R312: formation of a wide range of hydroxamic acids. Appl Environ Microbiol. 1998; 64: 2844-2852.

Geoghegan KF, Dixon HB, Rosner PJ, Hoth LR, Lanzetti AJ, Borzilleri KA, Marr ES, Pezzullo LH, Martin LB, LeMotte PK, McColl AS, 
Kamath AV, Stroh JG, Spontaneous alpha-N-6-phosphogluconoylation of

a "His tag" in Escherichia coli: the cause of extra mass of 258 or $178 \mathrm{Da}$ in fusion proteins. Anal Biochem. 1999; 267: 169-184.

Mayaux J, Cerebelaud E, Soubrier F, Faucher D, Petre D, Purification, cloning, and primary structure of an enantiomerselective amidase from Brevibacterium sp. strain R312: structural evidence for genetic coupling with nitrile hydratase. J Bacteriol. 1990; 172:6764-6773. member of the amidase signature family. FEBS J. 2007; 274(13):34403451.

Ohtaki A, Murata K, Sato Y, Noguchi K, Miyatake H, Dohmae N, Yamada K, Yohda M, Odaka M, Structure and characterizationof amidase from Rhodococcus sp. N-771: insight into the molecular mechanism of substrate recognition. Biochim Biophys Acta. 2010; 1804(1):184-192.

Politi L, Chiancone E, Giangiacomo L, Cervoni L, d'Abusco AS,

Scorsino S, Scandurra R, pH-, temperature- and iondependent oligomerization of Sulfolobus solfataricus recombinant amidase: a study with site-specific mutants. Archaea. 2009; 2:221-231. biochemical characterization of the amidase from hyperthermophilic archaeon. Sulfolobus solfataricus. Extremophiles. 2001; 5:183-192. 
391 Galadari S, Wu BX, Mao C, Roddy P, El Bawab S, Hannun YA,

392 Identification of a novel amidase motif in neutral ceramidase. Biochem J.

$3932006 ; 393(3): 687-695$.

394 Weatherburn MW, Phenol-hypochlorite reaction for determination of 395 ammonia. Anal Chem. 1967; 39:971-974.

396 Fenical W, Jensen PR, Developing a new resource for drug discovery:

397 marine actinomycete bacteria. Nat Chem Biol. 2006; 2: 666-673.

398 Shen W, Chen H, Jia K, Ni J, Yan X, Li S, Cloning and characterization

399 of a novel amidase from Paracoccus sp. M-1, showing aryl acylamidase

400 and acyl transferase activities. Appl Microbiol Biotechnol. 2012;

$401 \quad 94: 1007-1018$. 
Salinispora arenicola CNS-205 Rhodococcus Sp. N771

Thermus thermophilus HB8 Thermus thermophilus HB8 Thermotoga maritima MSB8

Salinispora arenicola CNS-205 Rhodococcus Sp. N771

Thermus thermophilus HB8 Thermus thermophilus HB8 Thermotoga maritima MSB8

Salinispora arenicola CNS-205 Rhodococcus Sp. N771

Thermus thermophilus HB8 Thermus thermophilus HB8 Thermotoga maritima MSB8 $\ldots . .$. LPLAGVPVAVKEN T A V AGLP TWNGS A A AR SPVA S I PPTSDGVLTGRRVA I KDNVTVAGVP MMNGSRTVEGF TP $\ldots . . . . P L H G L P L T V K D L F P V K G M P T R A G T K A P L P P L P$

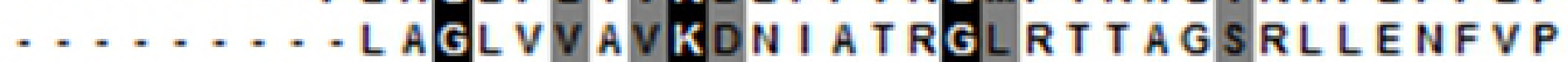
$\ldots . . . . . . F W G$ I PV A I KDN I L TLGMRT TCASR ILENYES

E ADHEVVRRLRGAGAVILGVTRMPELGLWGTTDD - A T AVT SRDATVVTRLLAAGATVAGKAVCEDLCFSGSSFTPASGPV - EE AR AVRRLRE AGALLFAKTNMHE I ALG I TGENPWTGPV P YEAT AVARLKALGALVLGKTNLDEFGMGSSTEHSAFFPT VFDATVVKKMKEAGFVVVGKANLDEFAMGSSTERSAFFPT

RWPWEL GRT PGGS S GGS A A A V A A GL V P I AH A NDGLGSIR I 185 RNPWDRQRE AGG S S GG S A A L V A NGDVDF A I GGDQGG S IR I 198 RNA VDP SRQAGGS S GGS AV AV ALG I GLA SLG TDTGGS IRI 174 KNP F DP DRVPGGS S GGSAAALA A DLAPL AL G SDTGGSVRQ 168 RNPWDLERVPGGSSGGSAA AVSAGMVVAALGSDTGGSVRQ 188 


\section{6. $0 \mathrm{kDa}$} 66. $2 \mathrm{kDa}$ 45. $0 \mathrm{kDa}$ 35. $0 \mathrm{kDa}$ 25. $0 \mathrm{kDa}$ 

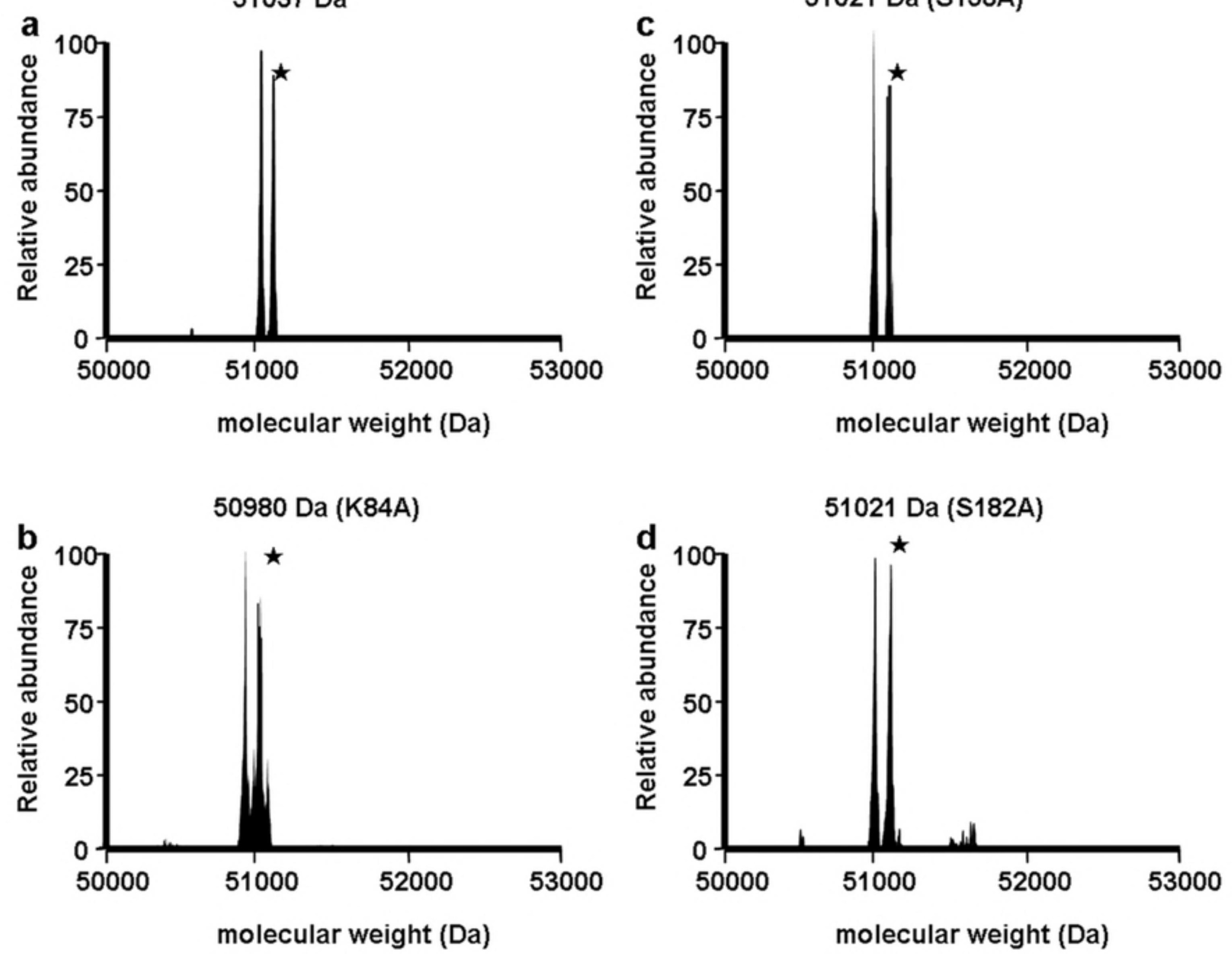
a

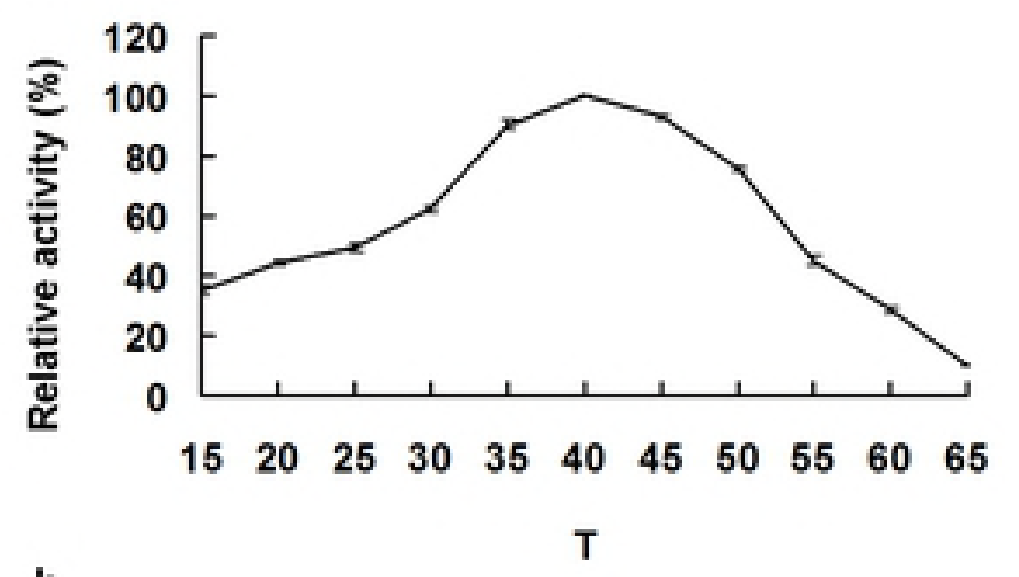

b

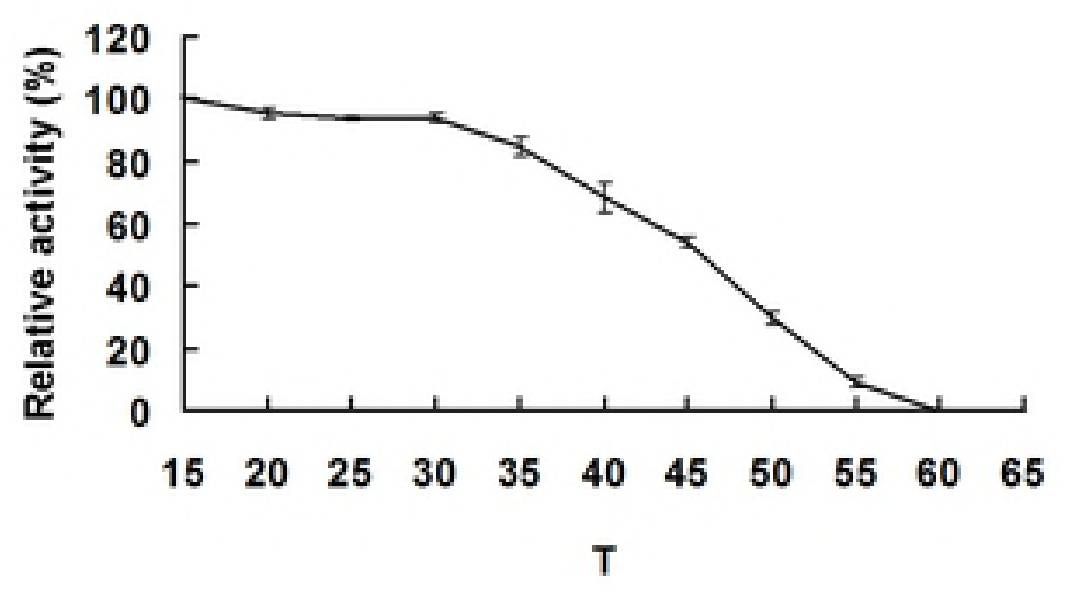

c

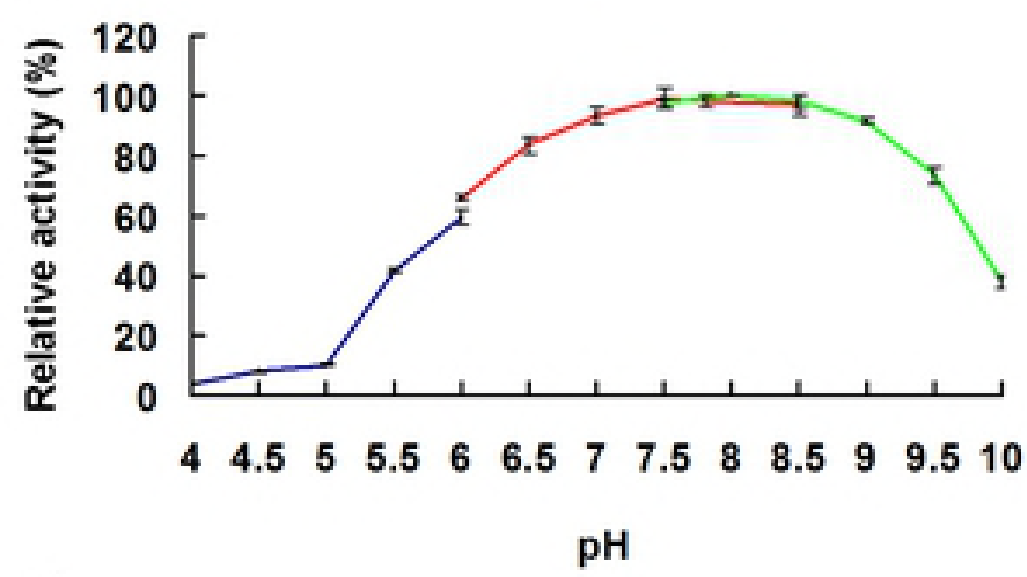

d

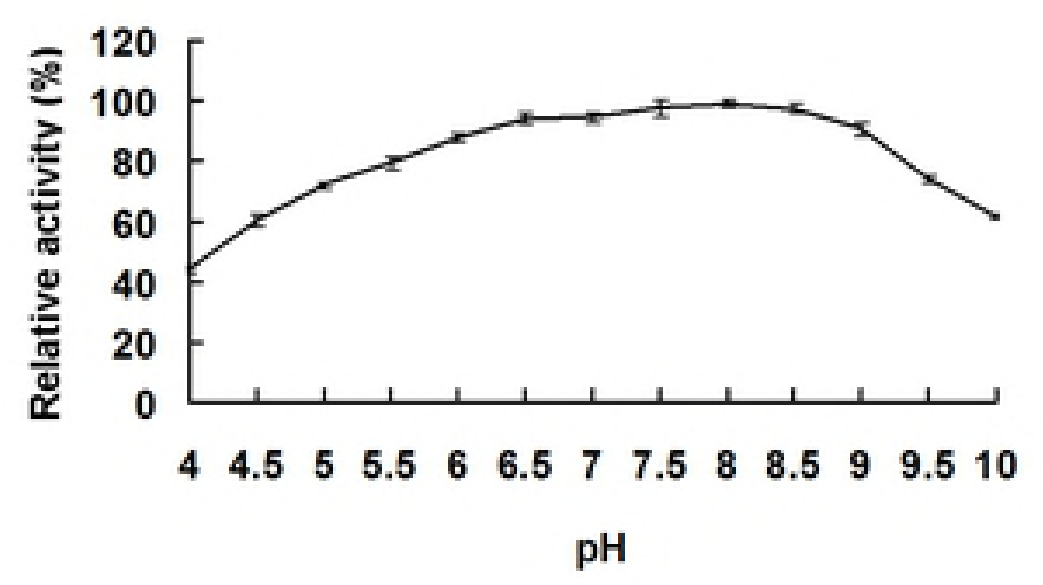

